\title{
Editorial
}

\section{NT-pro-BNP in cardiac surgery}

In this issue of the Heart, Vessels and Transplantation journal Akhmedova et al. (1) presents the relationship between preoperative testing of NT pro-BNP in routine cardiac surgery with clinical, perioperative variables, outcomes and complications in children and adults who have undergone cardiac surgery in a short period of time and based on a small sample of patients. Authors showed significant positive correlation between preoperative NT-pro-BNP and Euroscore II, which is an important finding, as results of previous studies were controversial $(2,3)$. They also found significant positive correlation between NT-pro-BNP and NYHA class, and need for inotropic support after surgery, and negative correlation with left ventricular ejection fraction and estimated glomerular filtration rate. Which means, preoperative NT-pro-BNP is related with early postoperative complications, markers of cardiac failure - low contractility, need for inotropic support, higher functional class and impaired renal function.

The NT pro-BNP concentration is of great importance in predicting the development of heart failure. NT pro-BNP has a so-called "negative predictive prognosis" - that is, the concentration is less than the level that requires making any decision, automatically excludes heart failure in a previously untreated patient $(4,5)$.

On the other hand, a high level of NT pro-BNP, in spite of optimal and correct treatment, indicates a poor prognosis. This article has not focused on preoperative treatment i.e. removal of signs of decompensation of heart failure. In addition to heart failure, high NT proBNP values can occur in the following conditions: left ventricular hypertrophy; overload of the right ventricle, tachycardia; arrhythmias, myocardial ischemia; hypoxemia, anemia, renal dysfunction, age, liver cirrhosis, sepsis; infection, which were not taken into account in this article, if only as a sign of exclusion from the study.

Further research is needed to determine its precise diagnostic and prognostic value in children (6). It was not considered whether cardioplegia during surgery affects the increase in NT pro-BNP. In my opinion, the effect of cardioplegic solution on NT pro-BNP levels should be further studied. There was no decrease in NT pro-BNP> $30 \%$ in response to treatment, and at what stage this was achieved. For a more precise control of the effectiveness of treatment, it is necessary to apply serial determination of the level of NT pro-BNP in comparison with the control based on monitoring of clinical parameters.

When interpreting the NT-proBNP level, it should be borne in mind that the criterion makes it possible to differentiate the normal function of the heart from dysfunction, the development of which is individual and asymptomatic at the initial stages. An increase in the level of the marker can be observed in atherosclerosis and cardiac fibrosis with an outcome in myocardial dysfunction.

The use of the laboratory criterion NT-proBNP makes it possible to objectively diagnose myocardial dysfunction with high analytical sensitivity and specificity; nevertheless, it is always necessary to compare complaints and echocardiography data with NT-proBNP data.

Timely assessment of NT-proBNP concentration allows predicting an unfavorable patient outcome. A number of authors report that it is advisable to determine the NT-proBNP test in ACS and CHF and opens up the possibility of screening for $\mathrm{CHD}$ and $\mathrm{CHF}$ in the early stages. - acute coronary syndrome and chronic heart failure, opens up the possibility of screening for coronary heart disease and chronic heart failure in the early stages.

Ikromzhon Mukhamedov Clinic Cardiac Surgery and Transplantation Center,

Taraz, Kazkahstan

Peer-review: Internal Conflict of interest: None to declare Authorship: I.M. Acknowledgement and funding: None to declare

Address for Correspondence: Ikromzhon Mukhamedov, Clinic Cardiac Surgery and Transplantation Center, Taraz, Kazkahstan

Email: ikrom_mukhamedov@mail.ru

Received: 15.08.2020 Accepted: 15.09.2020

Copyright (02020 Heart, Vessels and Transplantation

doi: $10.24969 /$ hvt.2020.216 


\section{References}

1.Akhmedova IA, Kudaiberdiev TZ, Abibillaev DA, Zhooshev AA, Zaripov DE, Tilemanbetova KT, et al. Relationship of preoperative NT-pro-BNP with clinical, perioperative and prognostic markers in cardiac surgery: Preliminary study results. Heart Vess Transplant 2020; 4:

2. Holm J, Vidlund M, Vanky F, Friberg O, Hakanson E, Walther $\mathrm{S}$, et al. EuroSCORE II and N-terminal pro-Btype natriuretic peptide for risk evaluation: an observational longitudinal study in patients undergoing coronary artery bypass graft surgery. BJA: Br J Anaesth 2014; 113: 75-82. doi: 10.1093/bja/aeu

3. Cuthbertson BH, Croal BL, Rae D, Harrild K, Gibson $\mathrm{PH}$, Prescott GJ, et al. N-terminal pro-B-type natriuretic peptide concentrations and long -term outcome after cardiac surgery: a prospective cohort study. $\mathrm{Br} J$ Anaesth 2013; 110: 214-21.

4. Ponikowski $P$, Voors AA, Anker SD, Bueno $H$, Cleland JGF, Coats AJS, et al. 2016 ESC guidelines for the diagnosis and treatment of acute and chronic heart failure. The $T$

ask Force for the diagnosis and treatment of acute and chronic heart failure of the European Society of Cardiology (ESC). Developed with the special contribution of the Heart Failure Association (HFA) of the ESC. Eur Heart J 2016; 37; 2129-200.

5. Cowie MR, Struthers AD, Wood DA, Coats AJ, Thompson SG, Poole-Wilson PA, et al. Value of natriuretic peptides in assessment of patients with possible new heart failure in primary care. Lancet 1997; 350: 1349-53.

6. Lin C, Zeng X, Jiang S, Wu T, Wang J, Zhang J, et al. Role of the NT-pro-BNP level in the diagnosis of pediatric heart failure and investigation of novel combined diagnostic criteria. Exp Ther Med 2013; 6: 995-9. doi.org/10.3892/etm.2013.1250.

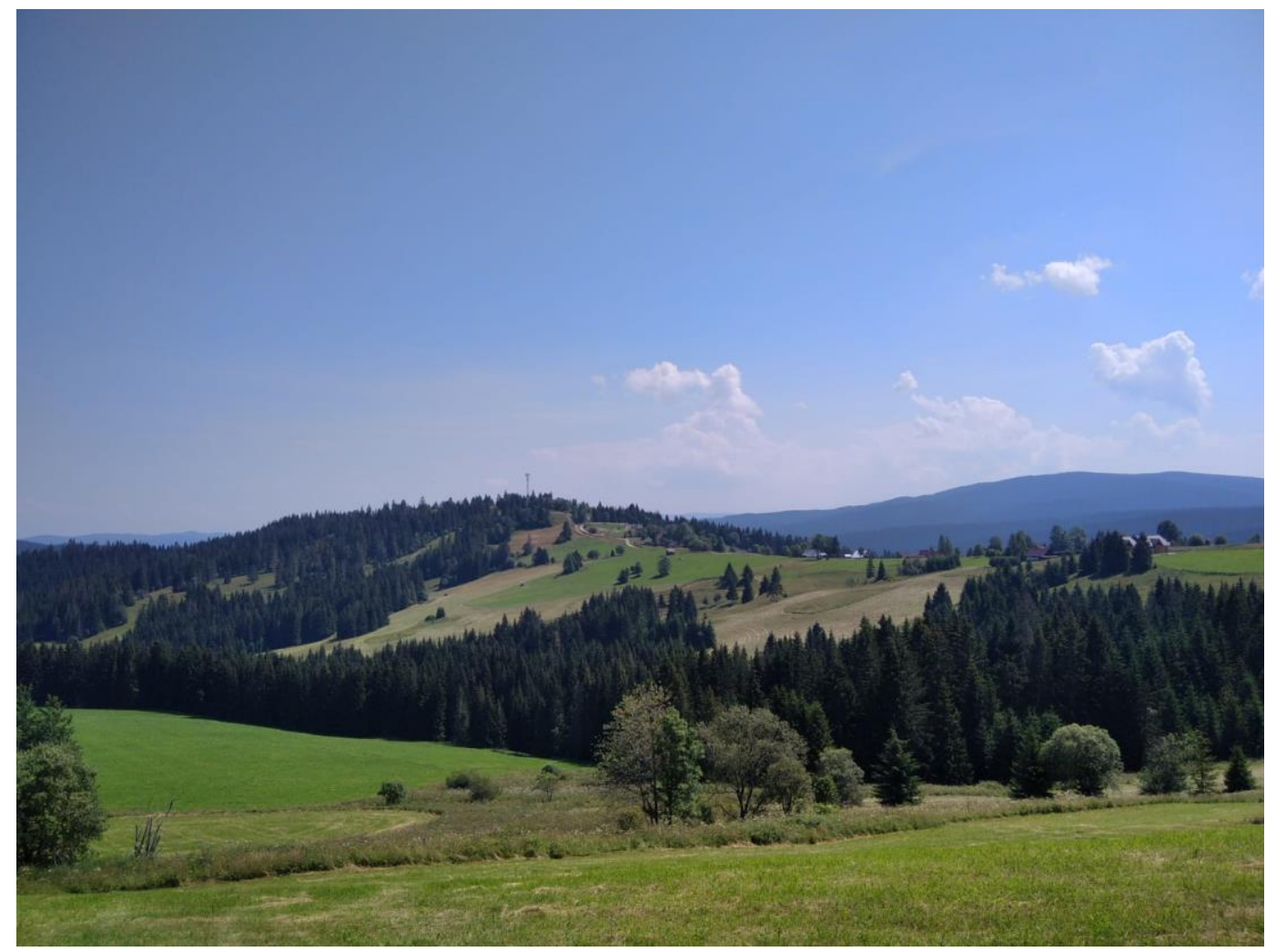

Horna Orava, North West Slovakia, Summer 2020, Lubica Murinova, Bratislava, Slovakia 
